\title{
Central Pontine Myelinolysis Associated with Cyclosporine in a Patient with NK Cell Leukaemia after Hematopoietic Stem Cell Transplantation
}

\author{
Case Report
}

Cheong MA*, Tan CW, Linn YC, Hwang WYK

Department of Haematology, Singapore General Hospital, Singapore.

\section{Abstract}

Central pontine myelinolysis (CPM) has been described as a rare complication of liver transplantation. Cases in allogeneic hematopoietic stem cell transplant are less reported. We present a patient with NK cell leukaemia who underwent allogeneic hematopoietic stem cell transplant and had progressive altered mental status and neurological deterioration. Clinical and radiological findings were consistent with CPM. The patient had hepatic impairment and was on cyclosporine at the time of diagnosis of CPM, both are common risk factors for development of CPM in the post-transplant setting. Patient was managed in the intensive care unit. A trial of corticosteroids was given and immunosuppressive agent was switched from cyclosporine to sirolimus. Patient regained full neurological function from this CPM episode.

Keywords: Central Pontine Myelinolysis; Cyclosporine; Leukaemia; Hematopoietic Stem Cell Transplant; Corticosteroids.

Abbreviations: Central Pontine Myelinolysis (CPM); Extrapontine Myelinolysis (EPM); Hematopoietic Stem Cell Transplant (HSCT); Intensive Care Unit (ICU); Magnetic resonance imaging (MRI).

\section{Introduction}

Central pontine myelinolysis (CPM) was first described by Adams et al. in 1959 as an acute non-inflammatory demyelinating disease affecting the central basis pontis [1]. While the pathogenesis is not clear, CPM has associations with chronic alcohol use, rapid osmolar shifts and liver transplantation. Thus far, only 2 cases of CPM after allogeneic hematopoietic stem cell transplant (HSCT) has been reported in the literature $[2,3]$. We describe a rare case that developed CPM after HSCT done for aggressive NK leukaemia and review the relevant literature for risk factors, clinical characteristics and management strategy.

\section{Case Presentation}

A 37-year-old female was diagnosed with aggressive NK cell leukaemia after presenting with a 3-week history of fever and lower limb skin rash. A bone marrow examination including flow cytometry, trephine biopsy and cytogenetics demonstrated the presence of Epstein-Barr virus positive aggressive NK cell leukaemia.

She was given SMILE protocol which comprised of dexamethasone $40 \mathrm{mg} /$ day on days 2 to 4 , methotrexate $2000 \mathrm{mg} / \mathrm{m}^{2}$ on day 1 , ifosfamide $1500 \mathrm{mg} / \mathrm{m}^{2} /$ day on day 2 to 4 , etoposide $100 \mathrm{mg} /$ $\mathrm{m}^{2} /$ day on day 2 to 4 . L-asparaginase, which was scheduled on day 8, was initially held off in view of severe sepsis but started on day 11 . The disease broke through on day 18 as evidenced by a re-emergence of skin rash and recurrent fevers. A repeat bone marrow examination revealed persistent disease.

She was then switched to BFM-R3 protocol which comprised of cytarabine $2000 \mathrm{mg} / \mathrm{m}^{2} /$ dose every 12 hours for 4 doses on day 1 to 3 , etoposide $150 \mathrm{mg} / \mathrm{m}^{2} /$ dose every 12 hours for 6 doses on day 3 to 5 and L-asparaginase 25000 units $/ \mathrm{m}^{2}$ on day 6 . The disease failed to achieve response with persistent disease demonstrated on bone marrow examination and skin biopsy.

She was started on GELOX protocol which comprised of gemcitabine $1000 \mathrm{mg} / \mathrm{m}^{2}$ on day 1 , oxaliplatin $150 \mathrm{mg} / \mathrm{m}^{2}$ on day $1, \mathrm{~L}$ asparaginase 6000 units $/ \mathrm{m}^{2} /$ day on day 1 to 5 . Unfortunately, this aggressive NK cell leukaemia remained refractory and persistent disease was demonstrated on a repeat bone marrow examination.

At this point, the patient was maintained on dexamethasone starting with $30 \mathrm{mg} /$ day. Her disease seemed to be under control with complete lysis of fever, resolution of rash and stable laboratory results.

\footnotetext{
*Corresponding Author:

Cheong May Anne,

Resident, Singhealth Internal Medicine, Department of Haematology, Level 3, Academia Building, Singapore General Hospital, 20 College Road Singapore 169856, Singapore. Tel: +6596746613

Email: mayanne.cheong@mohh.com.sg

Received: December 16, 2015

Accepted: December 21, 2015

Published: January 04, 2016

Citation: Cheong MA, Tan CW, Linn YC, Hwang WYK (2016) Central Pontine Myelinolysis Associated with Cyclosporine in a Patient with NK Cell Leukaemia after Hematopoietic Stem Cell Transplantation. Int J Stem Cell Res Transplant 04(1), 142-145. doi: http:// dx.doi.org/10.19070/2328-3548-1600024

Copyright: Cheong MA $^{\circ}$ 2016. This is an open-access article distributed under the terms of the Creative Commons Attribution License, which permits unrestricted use, distribution and reproduction in any medium, provided the original author and source are credited.
} 
There was no HLA-matched sibling or matched unrelated donor and decision was made for double cord stem cell transplant. The conditioning regime consisted of fludarabine $25 \mathrm{mg} / \mathrm{m}^{2} /$ day on day -7 to -5 , cyclophosphamide $60 \mathrm{mg} / \mathrm{kg} /$ day on day -6 to -5 and total body irradiation \#6/ 1200rad/day on day -3 to -1 . The double cord stem cell was infused with cord blood unit \#1: 3.0 x 107 total nucleated cell $/ \mathrm{kg}, 1.38$ x 105 CD34+Cell Ct/ $\mathrm{kg}$ and cord blood unit \#2: 2.2 x 107 total nucleated cell/kg, 3.37 x 105 $\mathrm{CD} 34+\mathrm{Cell} \mathrm{Ct} / \mathrm{kg}$. Cyclosporine and myfortic was given as graftversus-host disease prophylaxis.

On day +5 , patient was first noted to have behavioural changes with disorganized, dysrthic speech and confusion. Subsequently, she developed progressive weakness to the point of complete paralysis involving all 4 limbs, bulbar palsy and gaze palsy on day +6 .

Unable to maintain her airway, she was intubated and admitted to the intensive care unit (ICU). Magnetic resonance imaging (MRI) brain was performed and revealed swelling of the basal ganglia, thalami, insular cortex and pons bilaterally along with a symmetrical hyperintensity in T2 weighted, FLAIR and DWI imaging suggestive of CPM and extrapontine myelinolysis (EPM) (Figure 1).

At this point, the diagnosis of CPM was considered. It was noted that serum cyclosporine levels had been increasing in the days preceding the neurological deterioration and reached a peak of $537 \mu \mathrm{g} / \mathrm{L}$ on day +5 which was the day of neurological deterioration (Figure 2). Cyclosporine was stopped on day +6 and changed to sirolimus as an alternative immunosuppressant. Intravenous hydrocortisone at a dose of $50 \mathrm{mg}$ every 6 hours was also started. The patient's neurological status improved and she regained full neurological function on day +8 .

Serum sodium levels ranged from 134 to $144 \mathrm{mmol} / \mathrm{L}$ with no major fluctuations requiring correction in the week prior to the acute neurological deterioration. Total serum bilirubin levels were noted to be increasing prior to the deterioration (Table 1). Serum ammonia was $45 \mu \mathrm{mol} / \mathrm{L}$.

The patient displayed features of sepsis and became hemodynamically unstable on day +17 requiring high levels of inotropic support in the ICU. This was complicated by disseminated intravascular coagulopathy and oliguric acute kidney injury. She eventually demised on day +20 .

\section{Discussion}

Central pontine myelinolysis is a rare neurological disorder characterized by non-inflammatory demyelination involving the pons but can also affect other parts of the central nervous system [4]. The condition was first described by Adam et al. in alcoholics and the malnourished [1]. Although the exact pathophysiology of CPM is still not defined, multiple risk factors and associations have been identified. CPM is traditionally reported in patients with rapid osmolar shifts, classically rapid corrections of serum sodium [5]. Patients undergoing liver transplant were considered a high risk group for developing CPM [6]. By contrast, CPM as a complication after allogeneic HSCT is rare. To the best of our knowledge, there have only been two cases reported in the literature $[2,3]$.

The first case report described a patient who underwent HSCT which was complicated by severe hepatic veno-occlusive disease and required ventilatory support in the ICU. The patient had a failed extubation and subsequently discovered to have developed pseudo-bulbar palsy, gaze palsy and generalized weakness. A MRI brain performed confirmed the diagnosis of CPM. Supportive management in the ICU was continued but patient did not have any clinical improvement and demised [2]. The second case described a patient who had a deterioration in mental status. Since the initial MRI brain was non-specific, differentials such as uremic encephalopathy and central nervous system infection were considered. A follow-up MRI brain a few days later showed findings consistent with CPM. A trial of corticosteroids and plasmapheresis was instituted but patient did not have significant neurological recovery and demised [3].

In both cases, the patients did not have any significant improvement in their neurological status. By contrast, our patient had complete reversal of the initial neurological deficits. In all three cases, progressive worsening hepatic function was seen and cyclosporine was used as an immunosuppressive agent. Sodium levels were also stable in these cases with no rapid correction instituted. This has been correlated to some of the risk factors highlighted in studies among liver transplant patient who developed CPM [7]. In the setting of an allogeneic HSCT, neurological deterioration is common and multiple differentials have to be entertained [8]. While the diagnosis of CPM is confirmed on brain imaging, this may be a delayed finding as seen in the case reported by $\mathrm{Lim} \mathrm{KH}$ et al. [3,9]. Therefore, a high index of clinical suspicion based on

Figure 1. MRI Brain showing patchy hyperintensities within the pons suggestive of CPM.

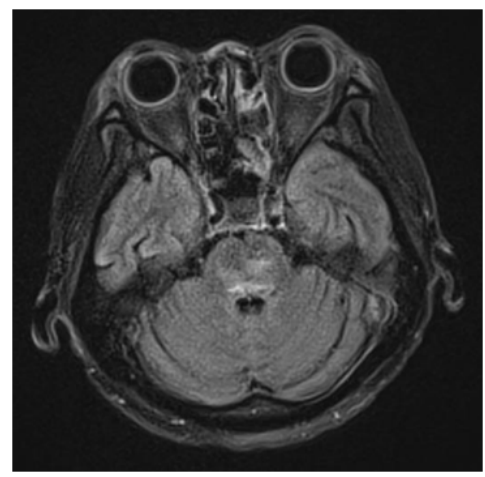

Figure 1a: MRI (FLAIR) imaging

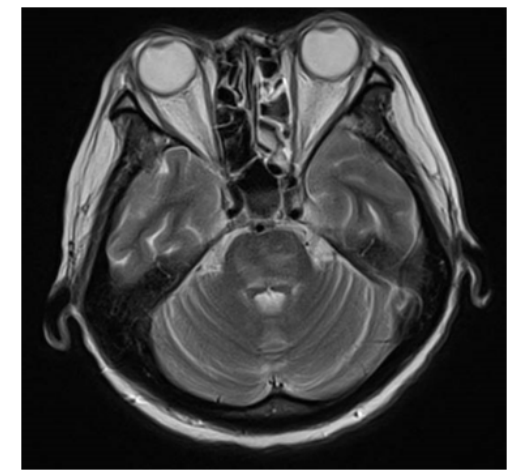

Figure 1b: MRI (T2 weighted) imaging 
Figure 2. Trend of sodium, cyclosporine and total bilirubin levels.

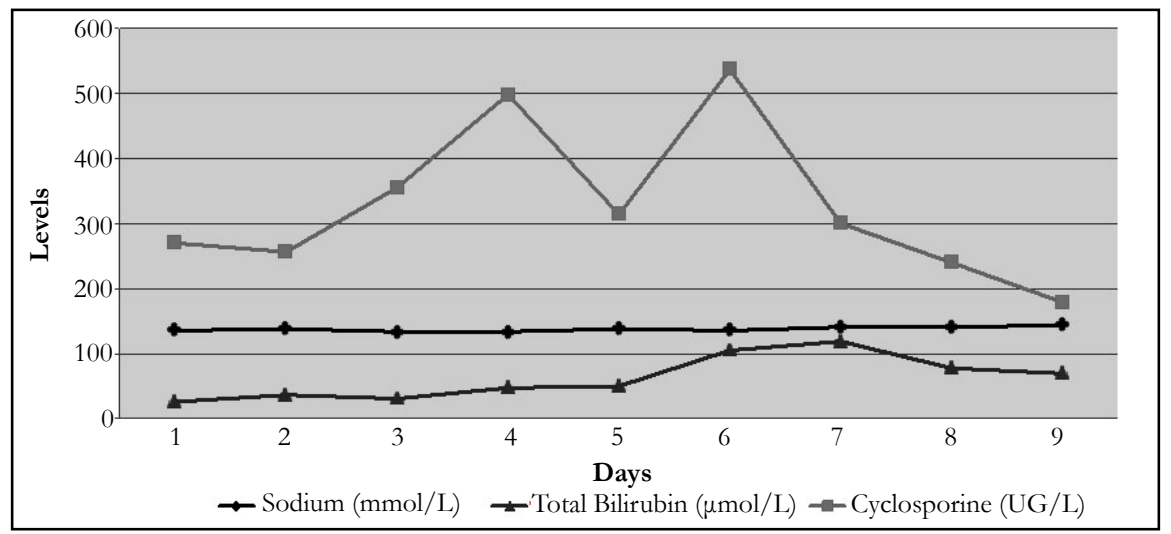

Table 1. Sodium, cyclosporine and bilirubin levels.

\begin{tabular}{|c|c|c|c|c|c|c|c|c|c|}
\hline Day & $\mathbf{0}$ & $\mathbf{+ 1}$ & $\mathbf{+ 2}$ & $\mathbf{+ 3}$ & $\mathbf{+ 4}$ & $\mathbf{+ 5}$ & $\mathbf{+ 6}$ & $\mathbf{+ 7}$ & $\mathbf{+ 8}$ \\
\hline Sodium $(\mathrm{mmol} / \mathrm{l})$ & 135 & 137 & 134 & 134 & 137 & 136 & 140 & 142 & 145 \\
\hline Cyclosporine $(\mathrm{UG} / \mathrm{L})$ & 270 & 256 & 355 & 499 & 314 & 537 & 300 & - & 179 \\
\hline Total Bilirubin $(\mu \mathrm{mol} / \mathrm{L})$ & 26 & 36 & 31 & 48 & 51 & 104 & 120 & 79 & 70 \\
\hline
\end{tabular}

risk factors, clinical progression and physical signs is important for early diagnosis and empirical management while awaiting sequential brain imaging [10].

The management of CPM is not well defined but there are case reports and series to demonstrate the beneficial effects of various treatment modalities. In our patient, we switched immunosuppressive agents and employed corticosteroids therapy. The neurological toxicity of calcineurin inhibitors is well documented and is a class effect with cases involving cyclosporine or tacrolimus reported [11-12]. Takeguchi et al. have suggested calcineurin inhibitors limit p-glycoprotein expression on central nervous system endothelial cells leading to enhanced nitric oxide production subsequently resulting in dysfunction of the blood-brain barrier and increased susceptibility to vasogenic oedema [13]. Hence, stopping the offensive agent and switching to alternative immunosuppression is a theoretical management option. m-TOR inhibitors including sirolimus and everolimus do not appear to have associated neurological complications and have been suggested as possible alternative immunosuppressive agents [14]. There are case reports of successful conversion to other such agents with good neurological outcomes in liver transplant patients $[15,16]$.

The use of corticosteroids in the treatment of CPM has been described in animal models, case reports and series. In rodent models, corticosteroids was demonstrated to have a protective effect via inhibition of mediators like tumour necrosis factor and prostaglandins, therefore preventing disruption of the bloodbrain barrier [17]. Dexamethasone was the most commonly used agents and have repeatedly shown varying degrees of neurological recovery in animal models $[18,19]$. In addition, there is emerging data from animal model studies suggesting that the timing of corticosteroids therapy is correlated with the degree of neurological outcomes. Ke QH et al. suggested that the early use of dexamethasone inhibited both disruption of the blood-brain barrier and prevent inducible nitric oxide synthase expression hence limiting development of demyelinating lesions. These effects were lost if dexamethasone administration was delayed [20]. This highlights the importance of early recognition and institution of manage- ment for CPM.

There are several case reports and series demonstrating good outcomes with remission of neurological symptoms after treatment in patients $[21,22]$. The largest case series available was by Kallakatta et al. where 6 out of a series of 24 patients with CPM and/or EPM were treated with corticosteroids. Two patients had favourable outcomes defined by independence in activities of daily living [23].

Central pontine myelinolysis has classically been regarded as a neurological condition associated with high mortality and severe morbidity [24]. However, there are retrospectives studies that have shown good recovery in CPM in a significant proportion of cases [10]. In a French retrospective observational study of patients with CPM and EPM managed in the ICU, 56\% of 36 patients had good functional recovery after supportive management [25]. With further understanding of the disease pathology, prompt diagnosis and appropriate management options, outcomes can improve [23].

\section{Conclusion}

Neurological complications in the setting of an allogeneic HSCT is common, for which CPM is a rare but potentially reversible condition. A high index of suspicion is required in the diagnosis of CPM based identifying characteristic clinical signs and symptoms and being cognisant of the common risk factors. While treatment is not clearly defined, there are trial management options like the early use of corticosteroids and switching of immunosuppressive agents which may offer clinical benefit.

\section{Author's Contribution}

This patient was under the care of HYKW and LYC who provided medical details of the patient's condition and treatment. CMA and TCW helped draft the case report. All authors read and approved the final manuscript. 


\section{References}

[1]. Adams RD, Victor M, Mancall EL (1959) Central pontine myelinolysis: a hitherto undescribed disease occurring in alcoholic and malnourished patients. AMA Arch Neurol Psychiatry 81(2): 154-172.

[2]. Fraser C, Charnas L, Orchard P (2005) Central pontine myelinolysis following bone marrow transplantation complicated by severe hepatic venoocclusive disease. Bone Marrow Transplant 36(8): 733-734.

[3]. Lim KH, Kim S, Lee YS, Kim KH, Kim J, et al. (2008) Central pontine myelinolysis in a patient with acute lymphoblastic leukemia after hematopoietic stem cell transplantation: a case report. J Korean Med Sci 23(2): 324-327.

[4]. Wright DG, Laureno R, Victor M (1979) Pontine and extrapontine myelinolysis. Brain 102(2): 361-385.

[5]. Sterns RH, Riggs JE, Schochet SS (1986) Osmotic demyelination syndrome following correction of hyponatremia. N Engl J Med 314(24): 1535-1542.

[6]. Estol CJ, Faris AA, Martinez AJ, Ahdab-Barmada M (1989) Central pontine myelinolysis after liver transplantation. Neurology 39(4): 493-498.

[7]. Crivellin C, Cagnin A, Manara R, Boccagni P, Cillo U, et al. (2015) Risk factors for central pontine and extrapontine myelinolysis after liver transplantation: a single-center study. Transplantation 99(6): 1257-1264.

[8]. Bleggi-Torres LF, de Medeiros BC, Werner B, Neto JZ, Loddo G, et al. (2000) Neuropathological findings after bone marrow transplantation: an autopsy study of 180 cases. Bone Marrow Transplant 25(3): 301-307.

[9]. Dervisoglu E, Yegenaga I, Anik Y, Sengul E, Turgut T (2006) Diffusion magnetic resonance imaging may provide prognostic information in osmotic demyelination syndrome: report of a case. Acta Radiol 47(2): 208-212.

[10]. Singh TD, Fugate JE, Rabinstein AA (2014) Central pontine and extrapontine myelinolysis: a systematic review. Eur J Neurol 21(12): 1443-1450.

[11]. de Groen PC, Aksamit AJ, Rakela J, Forbes GS, Krom RA (1987) Central nervous system toxicity after liver transplantation. The role of cyclosporine and cholesterol. N Engl J Med 317(14): 861-866.

[12]. Eidelman BH, Abu-Elmagd K, Wilson J, Fung JJ, Alessiani M, et al. (1991) Neurologic complications of FK 506. Transplant Proc 23(6): 3175-3178.

[13]. Takeguchi N, Ichimura K, Koike M, Matsui W, Kashiwagura T, et al. (1993) Inhibition of the multidrug efflux pump in isolated hepatocyte couplets by immunosuppressants FK506 and cyclosporine. Transplantation 55(3): 646649
[14]. Fukazawa K, Nishida S, Aguina L, Pretto E Jr (2011) Central pontine myelinolysis (CPM) associated with tacrolimus (FK506) after liver transplantation. Ann Transplant 16(3): 139-142.

[15]. Forgacs B, Merhav HJ, Lappin J, Mieles L (2005) Successful conversion to rapamycin for calcineurin inhibitor-related neurotoxicity following liver transplantation. Transplant Proc 37(4): 1912-1914.

[16]. Cui R, Fayek S, Rand EB, Feygin T, Khrichenko D, et al. (2012) Central pontine myelinolysis: a case report and clinical-pathological review. Pediatr Transplant 16(6): E251-256.

[17]. Murase T, Sugimura Y, Takefuji S, Oiso Y, Murata Y (2006) Mechanisms and therapy of osmotic demyelination. Am J Med 119(7 Suppl 1): S69-73.

[18]. Oh MS, Choi KC, Uribarri J, Sher J, Rao C, et al. (1990) Prevention of myelinolysis in rats by dexamethasone or colchicine. Am J Nephrol 10(2): $158-161$.

[19]. Sugimura Y, Murase T, Takefuji S, Hayasaka S, Takagishi Y, et al. (2005) Protective effect of dexamethasone on osmotic-induced demyelination in rats. Exp Neurol 192(1): 178-183.

[20]. Ke QH, Liang TB, Yu J, Zheng SS (2006) A study of the pathogenesis and prevention of central pontine myelinolysis in a rat model. J Int Med Res 34(3): 264-271.

[21]. Hagiwara K, Okada Y, Shida N, Yamashita Y (2008) Extensive central and extrapontine myelinolysis in a case of chronic alcoholism without hyponatremia: a case report with analysis of serial MR findings. Intern Med 47(5): 431-435.

[22]. Sakamoto E, Hagiwara D, Morishita Y, Tsukiyama K, Kondo K, et al. (2007) [Complete recovery of central pontine myelinolysis by high dose pulse therapy with methylprednisolone]. Nihon Naika Gakkai Zasshi 96(10): 22912293.

[23]. Kallakatta RN, Radhakrishnan A, Fayaz RK, Unnikrishnan JP, Kesavadas C, et al. (2011) Clinical and functional outcome and factors predicting prognosis in osmotic demyelination syndrome (central pontine and/or extrapontine myelinolysis) in 25 patients. J Neurol Neurosurg Psychiatry 82(3): 326-331.

[24]. Gocht A, Colmant HJ (1987) Central pontine and extrapontine myelinolysis: a report of 58 cases. Clin Neuropathol 6(6): 262-270.

[25]. Louis G, Megarbane B, Lavoué S, Lassalle V, Argaud L, et al. (2012) Longterm outcome of patients hospitalized in intensive care units with central or extrapontine myelinolysis. Crit Care Med 40(3): 970-972. 